\title{
Student Off-Task Electronic Multitasking Predictors: Scale Development and Validation
}

\author{
Yuxia Qian1 and Li Li2
}

\begin{abstract}
In an attempt to better understand factors contributing to students' off-task electronic multitasking behavior in class, the research included two studies that developed a scale of students' off-task electronic multitasking predictors (the SOTEMP scale), and explored relationships between the scale and various classroom communication processes and outcomes. The first study inductively developed initial typologies for the SOTEMP scale, refined the scale item pool, and explored the dimensions of the scale. Subsequently, the second study validated the scale through a confirmatory factor analysis and by assessing different concurrently existing communication processes as well as students' perceived learning outcomes. Four factors were found: Lack of Class Relating, Technology Dependence, Class Easiness, and Overwhelmed feeling. Reliability and validity were established for the scale. Results indicated the SOTEMP scale was positively related to students' cognitive absorption, and negatively related to students' perception of their affective learning. However, the SOTEMP scale was not related to students' perceived cognitive learning. Limitations and implications for future research are discussed.
\end{abstract}

Keywords: off-task electronic multitasking, scale development, teaching, learning, technology

Multitasking is commonplace in the classroom. Easy access to electronic devices such as cell phones and laptops gives the "net generation" ample opportunities to engage in multitasking activities, such as text messaging, Internet surfing, and checking emails; This is increasingly associated with the use of electronic devices for both class-and non-classrelated activities. The scope of the current study focuses on off-task electronic multitasking(OTEM) - the use of electronic devices for non-class-related activities while attending class.

Even though the use of electronic devices could potentially enhance learning when it is directed toward on-task activities in class, it is recommended that teachers encourage judicious use of technology (Grinols \& Rajesh, 2014). Evidence indicates that our ability to engage in simultaneous tasks ranges from limited to virtually impossible (Hembrooke \& Gay, 2003). Since human ability to process information is limited (Best, 1986; Bourne, Dominowski, \& Loftus, 1979; Lang, 2000), off-task multitasking may moderate the attention to on-task activities. Research has found that people engaged in multitasking took longer to finish two tasks than had they concentrated on one task at a time (Rubenstein,

\footnotetext{
1 Department of Communication Studies, Kutztown University, 15200 Kutztown RD, Kutztown, PA19530, qian@kutztown.edu 2 Communication and Journalism Department, University of Wyoming, 125 College Dr., Casper, WY82601, LLi11@uwyo.edu
} 
Meyers, \& Evans, 2001). Off-task electronic multitasking (OTEM) is especially problematic in the classroom as it distracts students' attention from lectures and participation in classroom activities, thereby diminishing students' learning (Young, 2006). Recent experimental research also has discovered that multitasking using a laptop impedes classroom learning both for users and nearby peers (Sana, Weston, \& Cepeda, 2013). Therefore, OTEM in the classroom is often viewed as a major type of student misbehavior.

The current research examines factors that contribute to students' OTEM behavior. More specifically, it aims to develop a scale of student off-task electronic multitasking predictors (SOTEMP) through two areas of study. The first study inductively developed initial typologies for the SOTEMP scale, refined the scale item pool, and explored the dimensions of the scale. Subsequently, the second study validated the scale through a confirmatory factor analysis and by assessing different concurrently existing communication processes.

\section{Literature Review}

Although research has largely focused on the relationship between electronic multitasking and academic performance, a few studies have explored the predictors of student OTEM. These studies divide the predictors in two general categories: internal forces and external forces. The distinction between internal and external forces reflects the long-term naturenurture debate, which attributes one's behaviors to innate characteristics/needs or to environmental factors. External factors that can predict OTEM are teacher immediacy, student learning motivation, awareness of instructor monitoring, distraction by other students, and social norms. Internal factors include the degree to which OTEM can gratify the individuals' needs, the habit of using information and communication technologies, and technology dependence/internet addiction.

\section{External Forces on OTEM}

One commonly examined external factor is teacher behavior. Wei and Wang (2010) proposed that teacher immediacy might moderate students' texting behaviors in the classroom. Since high teacher immediacy could enhance the effectiveness of teacherstudent interactions and motivate students to engage in on-task learning activities, it might decrease students' off-task behaviors, such as text messaging in class. However, their result showed that teacher immediacy alone does not moderate students' texting behaviors during class. Gerow, Galluch, and Thatcher (2010) investigated another aspect of teacher behavior-student awareness of teacher monitoring. They hypothesized that this would negatively influence student intent to cyber-slack. They argued that teacher monitoring could lead to student compliance because students are aware of their behaviors being observed and the subsequent consequences of non-compliance. However, their results did not support the hypothesis.

Despite the lack of empirical support with regard to teacher immediacy and student awareness of teacher monitoring, teacher behavior in a more positive manner could affect OTEM through an impact on student engagement. Skinner \& Belmont (1993) found that teacher behavior which includes the two facets of behavioral and emotional engagement plays a large role in student engagement. Engaged students tend to show "sustained

Journal of the Scholarship of Teaching and Learning, Vol. 17, No. 2, April 2017.

josotl.indiana.edu 
behavioral involvement in learning activities accompanied by positive emotional tone" (Skinner \& Belmont, 1993, p.572). The lack of engagement, or disaffection, is marked by passivity, withdrawal, and distraction in behavior and boredom, anxiety, and frustration in emotion (Skinner, Furrer, Marchland, \& Kindermann, 2008). OTEM is one manifestation of lack of engagement in class. With easy access to electronic devices, a disengaged student is more likely to become distracted and engage in OTEM during class. However, studies are limited in the area of examining the effect of student engagement on OTEM, as well. Lee, Lin, and Robertson (2012) suggested that multitasking interferes with student engagement in their knowledge acquisition since "extraneous cognitive load...burdens the working memory" (p. 102). Hassoun (2015) observed that students, who sat at the front of the class and used electronic devices less, did better in class. Wei and Wang (2010) studied a related concept - student learning motivation and its relationship with texting behaviors in class. The results did not show a significant relationship between the two variables.

Another recurring theme in the literature is the role of social influence on electronic multitasking. For example, based on Lewin's Field Theory (1939), Gerow and colleagues (2010) found that social norms positively influence students' intent to cyber-slack-the intent to use the Internet for non course-related activities. When peers and friends think cyber-slacking is acceptable, individuals are more likely to report the intent to cyberslacking. The study also found two other external predictors - distraction by other students and awareness of instructor monitoring. Distraction by other students occurs when a student sees other students cyber-slacking and gets distracted, which comprises the observational aspect of social influence. Therefore, students are not only influenced by what other students think but also by what other students actually do.

Consistent with the findings of the above study, another study by Stephen and Davis (2009) confirms the role of social influence on electronic multitasking. Based on social influence model (Fulk, Schmitz, \& Steinfield, 1990), Stephen and Davis examined the predictors of electronic multitasking in organizational meetings. The result indicated that organizational norms for engaging in electronic multitasking offer a unique and significant contribution to electronic multitasking in organizational meetings above and beyond individual-level predictors. They mentioned that observation of others' behaviors and perceptions of others' thoughts concerning electronic multitasking will predict individuals' own multitasking in organizational meetings.

Stephen and Davis (2009) also considered another situational factorcommunication overload and its effect on electronic multitasking in organizational meetings. They maintained that people who believe they are overloaded might engage in electronic multitasking to compensate for the effect of being overloaded. The results did not show a significant relationship between communication overload and electronic multitasking.

\section{Internal Forces on OTEM}

In comparison with external factors, most research suggests that internal factors influence electronic multitasking to a greater extent (Gerow, et al., 2010; Wei \& Wang, 2010). A few studies adopt the Uses and Gratifications Theory (UG Theory) to examine the internal motives/needs for electronic multitasking (Jeong \& Fishbein, 2007; Wei \& Wang, 2010). The UG Theory holds that social and psychological needs and motives drive audiences to

Journal of the Scholarship of Teaching and Learning, Vol. 17, No. 2, April 2017.

josotl.indiana.edu 
make use of different media to derive gratification (Jamal \& Melkote, 2008; Rubin, 1994, cited in Zhu \& He, 2002). For example, with a UG perspective, individuals use media to satisfy their needs and the most common gratifications they obtained from watching TV programs are to escape, to be entertained, to relieve boredom, to reduce loneliness, and to learn (Abrams \& Giles, 2007). Based on UG theory, research supported that internal gratifications of text-messaging are positively related to the frequency of text-messaging in class (Wei \& Wang, 2010). Five constructs of internal gratifications were measured in the study: affection, escape, inclusion, pleasure, and relaxation.

Similarly, Gerow, et al. (2010) identified five aspects of cognitive absorption as the internal factors of cyber-slacking. Cognitive absorption was defined in the study as a state of deep involvement with a particular task. The concept of cognitive absorption (Agarwal \& Karahanna, 2000) is composed of five dimensions: temporal dissociation (the loss of sense of time while a person is engaged in a particular activity); focused immersion (the experience of total engagement while other demands are ignored); heightened enjoyment (the pleasure from an activity); control (the perception of being in charge); and, curiosity (the extent the experience arouses an individual's curiosity). The five dimensions tap into the internal needs, which an activity/medium can meet. When individuals are cognitively absorbed with modern technologies, they tend to lose track of time and thereby reduce their on-task learning activities. The results showed that the overall construct of cognitive absorption positively influences intent to cyber-slack with only one non-significant dimension-control. Another internal motive/need that predicts multitasking with media in general is sensation-seeking - the need for varied, novel, and complex sensations and experiences (Jeong \& Fishbein, 2007).

Besides internal gratifications, habit or previous experience with electronic devices use was also identified as a significant internal predictor of electronic multitasking. Wei and Wang (2010) use the automaticity theory to argue that frequent use of text-messaging might become a habit over time, which may be defined as "automatic behaviors triggered by minimum consciousness" (p. 482). Students' daily texting usage significantly predicts text-messaging in class. For example, Olmstead and Terry (2014) found that one's frequency of texting in other contexts such as while driving or studying predicts texting in class. Based on social influence model, Stephen and Davis (2009) found that people's previous experience with technology will positively affect their electronic multitasking during organizational meetings.

The habit of technology use could even go to the extent of addiction. Researchers use such terms as "technology dependence" and "compulsive internet use/internet addiction" to describe such a condition (Byun, et al., 2009; Chang, 2012). Chang (2012) posited that modern information and communication technologies (ICTs) have evolved from once single-purpose oriented to general-purpose oriented, allowing users to perform a variety of tasks simultaneously. The nature of modern ICTs further fosters students' multitasking behaviors. Studies have shown that heavy users of ICTs are more likely to engage in multitasking behaviors (Garrett \& Daziger, 2008). Experimental research even revealed that most college students are not only unwilling but also unable to live without the Internet connection with the external world, thus becoming "technology dependent" (Moeller, et. al., 2010). Chang (2012) proposed that there is a positive relationship between technology dependence and student multitasking behaviors, yet this proposition has not been tested in empirical studies.

Journal of the Scholarship of Teaching and Learning, Vol. 17, No. 2, April 2017. josotl.indiana.edu 
Although the topic of electronic multitasking has begun to gain research attention, there are few studies on the causes of electronic multitasking. For example, Wei and Wang (2010) pointed out one of their study limitations of not assessing whether or not students' self-control and self-efficacy have any influence on texting behaviors in class. Self-efficacy is defined as individuals' belief in their ability to perform a specific task in a given situation or context (Bandura, 1986). Previous research suggested that self-efficacy and sense of personal control could contribute to the further use of mobile text messaging (Mahatanankoon \& O'Sullivan, 2008). In the case of electronic multitasking, it can be reasoned that individuals are more likely to multitask if they believe they have the ability to perform a variety of tasks simultaneously without much difficulty.

Another limitation of the few existing studies on causes of electronic multitasking is that they used the theory-driven hypotheses testing approach. Each study includes only a few predictor variables from its own particular theoretical lens, and thereby giving an incomplete picture. No known studies have investigated the causes of electronic multitasking by inductively collecting empirical data from the participants themselves and testing them among the participants. This study intends to fill the literature gap by developing a scale to predict electronic multitasking in the classroom.

\section{Study 1}

\section{Method of Stage 1}

Participants. A total of 116 students (50.9\% females; $49.1 \%$ males) from two U.S. universities took part in the study. The mean age of the participants was 21.51 years $(S D=$ 5.86). Participants reported predominantly as Caucasians (80.2\%) with African American as the second largest racial and ethnic group (9.5\%).

Design and Procedure. After the approval of Institutional Review Board, we emailed our colleagues in two universities in the U.S. to recruit their students to complete paper-based questionnaires. All students earned a small amount of extra credit for their participation. On each questionnaire, we defined classroom electronic multitasking as students' use of electronic devices such as cell-phones, laptops, I-pads, etc. to conduct activities that are not related to the course being taught at the time. We also listed some behaviors such as checking email, browsing Facebook, and text messaging. We then asked participants to think about factors/situations that might lead them to be engaged in electronic multitasking behavior in class. We asked each participant to record up to five factors or situations. At the end of each questionnaire, we asked participants for related demographic information.

Generation of initial scale items. Altogether, 484 messages describing the factors for engaging in electronic multitasking were generated from the participants. Using the constant comparative method (Glaser \& Strauss, 1967), two researchers met several times to discuss each message and were able to identify 53 student multitasking predictors. The process of refining the categories was iterative to establish validity. Face validity was established by using the participants' actual wording examples to phrase the predictors. Meanwhile, since all the predictors were created and grounded from the participants'

Journal of the Scholarship of Teaching and Learning, Vol. 17, No. 2, April 2017.

josotl.indiana.edu 
messages, the predictor pool achieved internal validity as well.

\section{Method of Stage 2}

Participants. Another groups of 199 students (males: 38.2\%; females: 60.3\%; $1.5 \%$ unreported) at two U.S. universities participated in the study. The average age of the participants was 20.53 years old $(S D=3.60)$. The vast majority of the participants were Caucasian $(n=169,84.9 \%)$, with no other ethnic group accounting for more than $7 \%$ of the total.

Design and Procedure. An online survey including 53 student multitasking predictors was created to ask the participants to indicate the likelihood of each of the initial predictors to contribute to students' multitasking behavior in class. Specifically, we asked the participants to check the level of likelihood of each predictor on a scale of $5(1=$ very unlikely, and 5 = very likely).

The data were screened for missing values and outliers. Missing values $(1.08 \%)$ were imputed by the "multiple imputations" procedure in the LISREL 8.80 analysis program. Furthermore, Mahalanobis Distance is a standard procedure to detect multivariate outliers, which are unusual or extreme values and often distort a statistical result. To calculate Mahalanobis Distance for each case, the case ID was put as the independent variable with the predictors as the dependent variables. "Mahalanobis Distance is evaluated as $\chi^{2}$ with degrees of freedom equal to the number of variables" (Tabachnick \& Fidell, 2007, p. 99). The predictors scale includes 53 variables and thus all 53 Mahalanobis variables must be examined against 90.573 , which was the critical value of chi-square at $p$ $<.001$. Four cases' Mahalanobis Distance values exceeded 90.573, and therefore they were removed from the data file. The final predictors data set contained 195 cases.

Initial Development of the Instruments (EFA). Three major methodological issues are typically considered to test the dimensionality of a scale in EFA: a) method of factor extraction, b) the type of factor rotation, and c) the number of factors to be retained.

First, the decision was made between the two most used factor extraction methods in communication research: Principal Component Analysis (PCA) and Principal Axis Factoring (PAF). PCA focuses on the total variation that is shared among all the variables. It is therefore an appropriate procedure to "reduce the measured variables to a smaller set of composite components that capture as much information as possible in the measured variables with as few components as possible" (Park, Dailey, \& Lemus, 2002, p. 563). PAF emphasizes the unique variation specific to each variable. It helps locate the latent dimensions of observed variables. Hence, PAF is a preferable factor extraction method for scale construction (McCroskey \& Young, 1979; Park, et al., 2002). Therefore, PAF instead of PCA was used in the current project to refine the scales.

Second, a decision had to be made to choose between orthogonal and oblique rotation methods. Oblique rotation procedures (e.g., promax, oblimin, quartimin, etc.) differ from orthogonal procedures (e.g., varimax, equimax, quartimax, etc.) in that oblique analysis assumes the existence of correlations between all variables (McCroskey \& Young, 1979). Since it has been suggested that many constructs in communication research are expected to be correlated (Costello \& Osborne, 2005; McCroskey \& Young, 1979; Park,

Journal of the Scholarship of Teaching and Learning, Vol. 17, No. 2, April 2017. josotl.indiana.edu 
et al., 2002), an oblique rotation method was applied to the current study for more accurate results.

Third, five criteria were used to determine how many factors to retain in the Principal Axis Analysis: the eigenvalue test (i.e., eigenvalue > 1), the total variability close to $50-70 \%$ that can be counted by the factors, the Parallel Analysis, visual inspection of the scree plot, and the interpretability/face validity of rotated factors.

\section{The Student Off-Task Electronic Multitasking Predictor (SOTEMP) Scale}

Since a factor analysis procedure explores the underlying correlational structure for a data set, the communality of a variable should be above .50. Fifteen predictors were eliminated from the current scale due to the failure of not meeting the criterion.

Five criteria were used to determine how many factors to retain in the Principal Axis Analysis: the eigenvalue test (i.e., eigenvalue > 1), the total variability close to 50$70 \%$ that can be counted by the factors, the Parallel Analysis, visual inspection of the scree plot, and the interpretability/face validity of rotated factors.

An initial Principal Axis Factoring with a Promax rotation procedure (a typical oblique rotation procedure) was applied to the data. The KMO and Bartlett's Test showed that some significant correlations existed between the items in the multitasking predictor typology $\left(\chi^{2}=2149.04, d f=253, p<.05\right)$. Meanwhile, the Kaiser-Meyer-Olkin test of sampling adequacy (.876) larger than a value of .60 indicated that factor analysis was the appropriate procedure for the data in the scale established preliminarily.

Four factors' eigenvalues were greater than 1.0. According to Kaiser's rule of eigenvalues greater than 1, those four factors should be kept. The four-factor structure explained a variance of $66.12 \%$. A Parallel Analysis was performed by using "the Parallel Analysis Engine to Aid Determining Number of Factors to Retain" (Patil, Singh, Mishra $\&$ Donovan, 2008) to use the mean and the $95^{\text {th }}$ percentile approaches with 1000 replications with the sample size and number of variables being 195 and 38 respectively. Both the means and $95^{\text {th }}$ percentile approach showed that four factors could be kept since only the first four factors' eigenvalues were higher than the random data eigenvalues. Meanwhile, a Scree Plot showed that from the first four factors, there was a comparatively sharper bend.

The above information all suggested a four-factor structure. Fifteen items met the .60/.40-loading criterion advocated by McCroskey and Young (1979). Goodboy (2011) suggested that items with borderline loadings (close to .60) with a secondary loading not exceeding $50 \%$ of the primary loading should be retained. Therefore, item 10 met that threshold. The final scale included 16 items, maintaining a sufficient number of items in any particular factor (Table 1). 
Qian and Li

Table 1. Rotated Factor Structure of the Scale

Journal of the Scholarship of Teaching and Learning, Vol. 17, No. 2, April 2017.

josotl.indiana.edu 


\begin{tabular}{|c|c|c|c|c|}
\hline & \multicolumn{4}{|l|}{ Factor } \\
\hline & 1 & 2 & 3 & 4 \\
\hline 1. There is a lack of teacher-student interaction. & .812 & .044 & -.147 & -.073 \\
\hline 2. The class is large. & .781 & -.121 & .032 & -.099 \\
\hline $\begin{array}{l}\text { 3. The teacher does not seem to pay attention to what I am } \\
\text { doing. }\end{array}$ & .711 & -.017 & .018 & .084 \\
\hline $\begin{array}{l}\text { 4. The teacher has a relaxed policy on using electronic } \\
\text { devices in class. }\end{array}$ & 676 & .004 & .130 & -.087 \\
\hline 5. The class topic is boring. & .655 & .059 & -.013 & .159 \\
\hline 6. The class content is not going to be on the test & .611 & .000 & -.045 & .136 \\
\hline $\begin{array}{l}\text { 7. I am addicted to using my laptop, phone, ipad, or other } \\
\text { electronic devices. }\end{array}$ & -.092 & 1.011 & .005 & -.137 \\
\hline $\begin{array}{l}\text { 8. I am addicted to some Internet social networks, such as } \\
\text { Facebook, twitter, etc. }\end{array}$ & -.012 & .834 & -.051 & -.039 \\
\hline 9. I feel restless when I cannot use the internet/cell phone. & .058 & .608 & -.049 & .193 \\
\hline $\begin{array}{l}\text { 10. It's my habit to check the internet or my cell phone } \\
\text { frequently. }\end{array}$ & .070 & .495 & .180 & .193 \\
\hline 11. The class material is easy to understand. & .239 & -.004 & .756 & -.187 \\
\hline 12. I can easily understand the knowledge presented in class. & -.019 & .057 & .752 & -.019 \\
\hline 13. It is easy to understand the teacher. & -.231 & -.078 & .696 & .190 \\
\hline 14. I am too tired. & -.013 & -.043 & .052 & .715 \\
\hline 15. I need a mental break from class. & .128 & .043 & .015 & .636 \\
\hline 16. There is too much information presented in class. & -.049 & -.022 & -.074 & .633 \\
\hline Eigenvalue & 5.12 & 2.49 & 1.78 & 1.19 \\
\hline$\%$ of Variance & 31.99 & 15.54 & 11.15 & 7.45 \\
\hline Alpha & .86 & .85 & .76 & .70 \\
\hline
\end{tabular}

Note. Principal Axis Factoring with Promax rotation was used.

Journal of the Scholarship of Teaching and Learning, Vol. 17, No. 2, April 2017.

josotl.indiana.edu 
The four factors had strong face validity when analyzed in comparison to literature on student in-class electronic multitasking behavior. Factor 1, lack of class relating $(M=$ $2.91, S D=.89, r=.86$ ), consisted of six items related to students' inability to see that the class is relating to them, thus there is a lack of behavior control and engagement in class. Factor 2, technology dependence $(M=2.88, S D=1.04, r=.85)$, included four items describing ways in which students are addicted to technology. Factor 3, class easiness ( $M$ $=3.48, S D=.84, r=.76$ ), contained three items related to students' perception of lack of intellectual challenge in class. Factor 4, overwhelmed feeling $(M=2.96, S D=.91, r=.70)$, included three items that indicated students being overwhelmed. The four factors were partially significantly correlated (see Table 2 ). The scale's overall reliability was .86.

\section{Table 2. Correlation Matrix of Scale Dimensions}

\begin{tabular}{llll}
\hline Factors & 2 & 3 & 4 \\
\hline 1 & $.309 * *$ & .127 & $.350 * *$ \\
2 & - & $.265 * *$ & $.490^{* *}$ \\
3 & & - & $.214 * *$ \\
4 & & & - \\
\hline$* * p<.01$ & & &
\end{tabular}

\section{Study 2}

Study 1 provided initial evidence of validity, reliability, and dimensionality of the SEMP scale. To add further evidence of validity, Study 2 reported a confirmatory factor analysis and also assessed relationships between students' perceptions of SEMP, their cognitive absorption with modern technologies, and their affective as well as cognitive learning.

To test the model fit of the scale's four-factor structure, a confirmatory factor analysis procedure was performed with maximum likelihood estimation (ML) using LISREL 8.80 on predictors dataset $(N=215)$. Five popular model fit indices were used: (a) the normal theory weighted least squares chi-square, (b) the root mean square error of approximation (RMSEA), (c) comparative fit index (CFI), (d) the non-normal fit index (NNFI), and (e) the standard root mean square residual (SRMR). Model fit is generally considered acceptable if RMSEA statistics does not exceed .08 (and preferable less than .05), the values of CFI and NNFI are above .90, and SRMR value is less than .08 (Kline 2005; MacCallum, Browne, \& Sugawara, 1996). Ideally, the chi-square statistics should be non-significant. However, considering the large sample size involved in the CFA data analysis, the index was seldom non-significant; thus, it was not considered in the current data. To confirm the four-factor structure of the scale, an adequate model fit should be observed.

$\mathrm{H}_{1}$ : The four-factor structure observed in the first study will have adequate fit with the data set in Study 2.

Based on UG Theory, previous literature indicates that students' electronic multitasking is heavily influenced by their internal needs gratification. Similar to the internal gratifications, cognitive absorption captures "a broad range of feelings including control, curiosity, heightened enjoyment, focused immersion, and temporal dissociation" Journal of the Scholarship of Teaching and Learning, Vol. 17, No. 2, April 2017. josotl.indiana.edu 
(Gerow, et al., 2010, p. 9). The five dimensions of cognitive absorption are correspondent with several aspects of internal gratifications. In addition, cognitive absorption was defined as a state of deep involvement with a particular task. The definition shares a common characteristic with technology dependence: the deep level of involvement and focused immersion in technologies. Since both internal gratifications and technology dependence are internal forces driving electronic multitasking, it is expected that SOTEMP scale is positively related to students' cognitive absorption. Previous research also supported that cognitive absorption with modern technologies could lead to cyber-slacking (distractive internet use in class). Therefore, we proposed our second hypothesis as:

$\mathrm{H}_{2}$ : SOTEMP in the classroom are positively related to students' cognitive absorption with their electronic technologies.

As the common practice of instructional communication research, cognitive learning and affective learning were explored in the current study. Cognitive learning was defined as students' knowledge retention and knowledge in terms of learners' abilities and skills, such as comprehension, application, analysis, synthesis and evaluation of course information (Bloom, Englehart, Furst, Hill, \& Krathwohl, 1956; Mayer, 1998, 2008). It is widely acknowledged that teachers' primary and ultimate goal is to facilitate their students' cognitive learning (Ellis, 2004; Kearney, Plax, Richmond, \& McCroskey, 1985). Different from the knowledge emphasis of the cognitive learning, affective learning emphasizes students' "interests, attitudes, appreciations, values" (Krathwohl, Bloom, \& Masia, 1964, p.7). Accordingly, scholars suggest that teachers should focus on teaching valuing process, clarifying attitudes, preferences, motivation, values, building relationships between students, materials and teachers, etc. (Shechtman \& Leichtentritt, 2004). Affective learning objectives are widely regarded to lead to students' excellence and positive classroom environment. Students who are engaged in OTEM pay less attention to class lectures and activities. As a result, they tend to gain less from the class and have less cognitive learning. In addition, the students' act of engaging in non-class-related activities hinders the relationship building between teachers and students in class, which, in turn, influences the affective learning of students. Research has shown that OTEM negatively affects classroom learning and student performance (Sana, Weston, \& Cepeda, 2013). Therefore, we posited the following hypotheses:

$\mathrm{H}_{3}$ : SOTEMP in the classroom are negatively related to students' perception of affective learning.

$\mathrm{H}_{4}$ : SOTEMP in the classroom are negatively related to students' perception of cognitive learning.

\section{Method}

\section{Participants}

A third group of student participants took part in the study. A total of 217 students $(68.5 \%$ females; $26.9 \%$ males; $4.6 \%$ unreported) from two U.S. universities participated. The mean age of the participants was 19.64 years $(S D=2.27)$. Participants reported predominantly

Journal of the Scholarship of Teaching and Learning, Vol. 17, No. 2, April 2017.

josotl.indiana.edu 
as Caucasians (77.8\%) with no other ethnic groups reporting be more than $6 \%$ of the sample.

\section{Design and Procedure}

The data were again screened for missing values and outliers. The missing values (.69\%) for the SEMP Scale were computed by the "multiple imputations" procedure in the LISREL 8.80 analysis program. We opted to employ Mahalanobis Distance again to detect multivariate outliers. As the predictors scale includes 16 variables and thus all 16 Mahalanobis variables must be examined against 39.252, which was the critical value of chi-square at $p<.001$. Two cases' Mahalanobis Distance values exceeded 39.252, and therefore they were removed from the data file. The final predictors data set contained 215 cases.

\section{Instruments}

Cognitive Absorption Scale. Cognitive Absorption Scale (Agarwal \& Karahanna, 2000) consists of five dimensions: temporal dissociation, focused immersion, heightened enjoyment, control, and curiosity. The scale includes 10-items with the 5-point Likert response format ranging from strongly disagree to strongly agree. Sample items include, "I have fun interacting with the Internet while I'm in class" and "the class flies by when I'm using the Internet." The Cronbach Alpha for the scale in this study was .89.

The Revised Cognitive Learning Indicators Scale. The Revised Cognitive Learning Indicators Scale (RCLIS; Frymier \& Houser, 1999) includes seven items assessing learner behaviors or activities associated with learning course content. This scale makes use of a 5-point Likert response format ranging from 0 (never) to 4 (very often). In this study, numerical values of the responses were changed to the format ranging from 1 for "never," and 5 for "very often." Sample items include "I review the course content" and "I think about the course content outside the class.' Previous findings have demonstrated construct validity and satisfactory reliability, with alpha coefficients ranging from .83 to .86 (Frymier \& Houser, 1999; Hsu, 2012). In this study, Cronbach's alpha was .84.

The Affective Learning Scale. The Affective Learning Scale (ALS; McCroskey, 1994; McCroskey, Richmond, Plax, \& Kearney, 1985) includes 24-items measuring students' attitude towards the course, subject matter, and the teacher, as well as the likelihood of students' related behavior. Each of these dimensions is evaluated through four 7-point bipolar adjective subscales (good-bad, worthless-valuable, fair-unfair, and positive-negative). The scale has been repeatedly used and has shown a high reliability of .90 (McCroskey et al., 1985; Plax, Kearney, McCroskey, \& Richmond, 1986, Hsu, 2012). In this study, the scale's overall Cronbach's alpha was .97. Specifically, the reliability for the subscales were: affect towards the behaviors recommended in the course $(\alpha=.95)$, the class' content $(\alpha=.95)$, the instructor $(\alpha=.97)$, likelihood of taking future courses in the content area $(\alpha=.97)$, and likelihood of actually attempting to engage in behaviors recommended in the course $(\alpha=.98)$.

\section{Results}

Results of the CFA indicated that the four-factor model fit was acceptable: $\chi^{2}(98)=199$, Journal of the Scholarship of Teaching and Learning, Vol. 17, No. 2, April 2017. josotl.indiana.edu 
$p<.01 ; \mathrm{CFI}=.95, \mathrm{NNFI}=.94, \mathrm{SRMR}=.072, \mathrm{RMSEA}=.069[90 \% \mathrm{CI}=.055: .083] . \mathrm{An}$ inspection of the $\lambda$ loadings and accompanying $z$-scores indicated that all 15 items loaded significantly (factor loadings ranged from .53 to 1.05) on their respective factors (see Table 3).

\section{Table 3. Confirmatory Factor Analysis}

Journal of the Scholarship of Teaching and Learning, Vol. 17, No. 2, April 2017. 


\begin{tabular}{|c|c|c|}
\hline Latent Construct Item & $M \quad S D \quad \lambda$ & $S E$ \\
\hline \multicolumn{3}{|c|}{ Factor 1. Lack of Class relating } \\
\hline 1 & 2.891 .17 .92 & .08 \\
\hline 2 & 3.141 .23 .60 & .08 \\
\hline 3 & 2.741 .09 .84 & .07 \\
\hline 4 & 2.941 .19 .53 & .08 \\
\hline 5 & 3.031 .11 .71 & .08 \\
\hline 6 & 2.471 .28 .83 & .09 \\
\hline
\end{tabular}

Factor 2. Technology Dependence

7

8

9

10

Factor 3. Class Easiness

11

12

13

Factor 4. Overwhelmed Feeling

14

15

16
2.661 .20 .1 .05 .08

$2.731 .27 \quad 1.04 \quad .09$

$2.381 .08 .65 \quad .07$

$3.411 .24 .85 \quad .08$

$3.361 .10 .94 \quad .08$

$3.491 .05 .99 \quad .07$

$3.201 .11 .79 \quad .08$

Note. All factor loadings are standardized and significant at $p<.01$

The second hypothesis stated that SOTEMP are positively related to cognitive absorption with modern technologies. Simple correlations were run to test the second hypothesis as well as hypotheses 3 and 4 . The second hypothesis was supported, with $\mathrm{r}=.597, p<.001$. The third hypothesis predicted that SOTEMP in the classroom are Journal of the Scholarship of Teaching and Learning, Vol. 17, No. 2, April 2017.

josotl.indiana.edu 
negatively related to students' perception of affective learning. Hypothesis 3 was supported, with $r=-.206, p<.001$. More specifically, among the four factors of SOTEMP scale, only factor 1(lack of class relating) and factor 4 (overwhelmed feeling) were negatively related to students' perception of affective learning, with $r=-.174$ and $r=-.294$ respectively at the significance level of .001 $(p<.001)$. Factor 2 (technology dependence) and factor 3 (class easiness) were not significantly related to students' perception of affective learning, with $r=-.095$ and $r=-.007$ respectively, $p<.001$. Hypothesis 4 predicted that SOTEMP are negatively related to students' perception of cognitive learning. Hypothesis 4 was not supported, with $r=-.128, p=.068$. The statistic reports also showed that none of the four factors was significantly related to students' perceived cognitive learning.

\section{Discussion}

Despite the popularity of OTEM in the classroom, there are no existing scales to assess the predictors of student OTEM. This is the first study to develop such a scale. Four factors were retained from the SOTEMP scale: lack of class relating, technology dependence, class easiness, and overwhelmed feeling. The four dimensions reflect both internal and external forces that drive OTEM in the classroom, which is consistent with the literature.

Technology dependence and overwhelmed feeling are the internal factors; whereas, lack of class relating and class easiness are the external factors. Technology dependence (also labeled as internet addiction in the literature) describes the state that individuals are highly dependent on or even addicted to technology, which further fosters their electronic multitasking behaviors. The result is consistent with literature since similar concepts, such as cognitive absorption and media use habit, have been found to be significant predictors of electronic multitasking. In addition, individuals who are highly dependent on technology tend to always keep their electronic devices within easy access. In addition, easy access to media devices could lead to media multitasking (Jeong \& Fishbein, 2007). Overwhelmed feeling depicts the sense of feeling overwhelmed due to information overload or tiredness. The overwhelmed feeling could easily trigger a need for escape that can be satisfied through electronic multitasking and media consumption. The finding is consistent with the Uses and Gratification theory. To date, no studies have been found to indicate overwhelmed feeling as the cause of electronic multitasking. This is a new finding in our study. This finding also indicates that there is probably no clear-cut division between external and internal forces of electronic multitasking. Some situational factors, such as information overload, might trigger an internal need, which leads to electronic multitasking.

Lack of class relating refers to teacher behaviors of lack of involvement and monitoring of students' activities. Contrary to previous empirical studies, lack of class relating was found to be a significant predictor of OTEM in our study. Despite the lack of empirical support, this finding is supported by the student engagement theory since disengaged students tend to get distracted easily and conduct misbehaviors. OTEM is one manifestation of student misbehaviors in class. Class easiness as one of the causes of electronic multitasking hasn't been investigated before in the literature. However, it can be reasoned that class easiness could lead to students' self-efficacy of electronic multitasking in class. When students perceive the class content as easy or not challenging, they tend to have heightened self-efficacy of electronic multitasking - the belief that they have the ability to perform off-task activities simultaneously. Self-efficacy could contribute to the 
actual electronic multitasking behaviors in class. The two class-related external factors are the new findings that our study brings to the literature of student electronic multitasking.

In validating the SOTEMP scale, our study also supported the literature that students' electronic multitasking behaviors are heavily influenced by internal needs and individual characteristics. The study found that SOTEMP were positively related to students' cognitive absorption with their electronic technologies. The concept of cognitive absorption reflects both internal gratifications from and deep involvement with a particular task. The five dimensions of cognitive absorption taps into the internal needs for control, curiosity, and enjoyment. At the same time, the concept also captures the features of technology dependence in terms of deep involvement and focused immersion.

Although literature showed that electronic multitasking is only slightly influenced by external factors (Gerow, et al., 2010), our study suggested that students' affective learning is negatively related to SOTEMP scale. As affective learning reflects students' interests and attitudes toward the course and instructor, higher level of affective learning could lead to a positive classroom environment in which disruptive behaviors, such as electronic multitasking, are less likely to occur.

Surprisingly, our hypothesis that students' electronic multitasking predictors are negatively related to students' perception of cognitive learning was not supported. The surprising result might be related to the self-reported survey method. Discrepancies might exist between perceived cognitive learning and actual cognitive learning.

\section{Limitations and Future Directions}

The current program of research also has several limitations. First, the vast majority of the participants were Caucasian with an average of 20 years old. The findings might not be generalized to other age or ethnic groups. Future studies might incorporate a more diverse population. Secondly, this study used students' self-reports to measure their cognitive absorption with technology as well as their perceived affective and cognitive learning, which might be different from their actual behaviors. Future studies might report the frequency and duration of technology use in class and measure students' learning by assessing their actual performance in class. Thirdly, self-reports were also used to solicit the initial pool of scale items. The participants might be unaware of certain situations that could lead to electronic multitasking, whereas these situations could be quite visible to outside observers, such as teachers in the classroom. For example, in the literature, social influence has been identified as one of the causes of electronic multitasking, but this factor was not reflected in our initial pool of items. Future studies could also solicit teachers' reports on students' OTEM causes. In addition, experimental studies can also be conducted to monitor some particular situational factors that might contribute to students' electronic multitasking behaviors. Finally, the current research focused on off-task electronic multitasking, which distracts students from actively participating in class activities. However, with the advance of instructional technology, electronic devices can be used in many positive ways to enhance classroom learning experiences. For example, Lysne \& Miller (2015) examined ways to use mobile devices to engage students in evolutionary thinking. Ekanayake and Wishart (2015) discussed ways for teachers to integrate mobile phones into teaching and learning. Future studies could be conducted to examine on-task electronic multitasking and its positive effect on student learning.

Journal of the Scholarship of Teaching and Learning, Vol. 17, No. 2, April 2017.

josotl.indiana.edu 


\section{Conclusion}

Students' OTEM has been viewed as one of the major distractions from learning in the classroom (Fried, 2008). The current research makes an important contribution to student electronic multitasking by developing the first SOTEMP scale. This study has significant implications for both researchers and practitioners. First, previous research tends to attribute students' electronic multitasking to internal factors (Wei \& Wang, 2010; Gerow, et al., 2010). In the current study, we found external factors as well, such as lack of class relating and class easiness. To reduce OTEM, teachers might involve students more by having close interactions, paying more attention to student behaviors in class, and making the lectures more relevant to students' life and more entertaining. Just as Ferguson, Philips, Rowley, and Friedlander (2015) pointed out, to enhance classroom management, teachers need to work on encouraging student on-task behaviors by "teaching in ways that clarify, captivate, and challenge instead of merely controlling students through intimidation or coercion" (p. 12). Second, class easiness was also found to be a predictor of students' electronic multitasking. While trying to make the class materials easily understandable, teachers should also make the class topics intellectually challenging so that students would be more occupied in the lectures and class activities, and thereby leaving little room for multitasking. At the same time, teachers could vary their teaching formats in class so that students do not feel overwhelmed from information overload. Finally, technology dependence is one of the major factors in student electronic multitasking. Once forming the habit, students want to be connected all the time. They tend to engage in multitasking whenever they are given the chance. With easy access to various modern technological devices, it has become more common for students to engage in electronic multitasking. Thereby, it is unrealistic for teachers to monitor all off-task multitasking behaviors in class. Other than merely enhancing teacher monitoring, researchers and practitioners could generate various creative ways to productively integrate the technology use into on-task teaching and learning activities in the future.

\section{References}

Abrams, J., \& Giles, H. (2007). Hispanic American television activity: Is it related to vitality perceptions?. Conference Papers -- International Communication Association. Retrieved May 31, 2009, from Communication \& Mass Media Complete database.

Agarwal, R., \& Karahanna, E. (2000). Time flies when you're having fun: Cognitive absorption and beliefs about information technology usage. MIS Quarterly, 24, 665-694. Bandura, A. (1986). Chapter 9 Self-efficacy. In Social functions of thought and action (pp. 390-453). Englewood Cliffs, NJ: Prentice-Hall.

Best, J. B. (1986). Chapter 2 Attention and pattern recognition. In Cognitive psychology (pp. 34-71). St. Paul, MN: West Publishing.

Journal of the Scholarship of Teaching and Learning, Vol. 17, No. 2, April 2017.

josotl.indiana.edu 
Bloom, B., Englehart, M., Furst, E., Hill, W., \& Krathwohl, D. (1956). Taxonomy of educational objectives - the classification of educational goals, handbook I: The cognitive domain. New York: McKay.

Bourne, L., Dominowski, R., \& Loftus, E. (1979). Cognitive processes. Englewood Cliffs, NJ: Prentice-Hall.

Byun, S., Ruffini, C., Mills, J. E., Douglas, A. C., Niang, M., Stepchenkova, S., ... Blanton, M. (2009). Internet addiction: Metasynthesis of 1996-2006 quantitative research. Cyber Psychology \& Behavior, 12, 203-207.

Chang, T. (2012). Predictors of students' multitasking behavior. In P. Resta (Ed.), Proceedings of society for information technology \& teacher education international conference 2012 (pp. 3558-3563). Chesapeake, VA: AACE.

Costello, A. B., \& Osborne, J. W. (2005). Best practices in exploratory factor analysis: four recommendations for getting the most from your analysis. Practical Assessment, Research \& Evaluation, 10, 1-9.

Ekanayake, S. Y. \& Wishart, J. (2015). Integrating mobile phones into teaching and learning: A case study of teacher training through professional development workshops. British Journal of Educational Technology, 46 (1), 173-189.

Ellis, K. (2004). The impact of perceived teacher confirmation on receiver apprehension, motivation, and learning. Communication Education, 53, 1-20.

Ferguson, R. F., Philips, S. F., Rowley, J. F.S., \& Friedlander, J. W. (2015). The influence of teaching beyond standardized test scores: Engagement, mindsets, and agency. Retrieved May 23, 2016, from http://www.agi.harvard.edu/projects/TeachingandAgency.pdf

Fried, C. B. (2008). In-class laptop use and its effects on student learning. Computers \& Education, 50, 906-914.

Frymier, A.B., \& Houser, M.L. (1999). The revised learning indicators scale. Communication Studies, 50, 1-12.

Fulk, J., Schmitz, J., \& Steinfield, C. W. (1990). A social influence model of technology use. In J. Fulk \& C. Steinfield (Eds.), Organizations and communication technology (pp. 117-140). Newbury Park, CA: Sage.

Garrett, R. K., \& Danziger, J. N. (2008). IM= Interruption management? Instant messaging and disruption in the workplace. Journal of Computer Mediated Communication, 13(1), $23-42$.

Gerow, J. E., Galluch, P. S. \& Thatcher, J. B. (2010). To slack or not to slack: Internet Journal of the Scholarship of Teaching and Learning, Vol. 17, No. 2, April 2017. 
usage in the classroom. Journal of Information Technology Theory and Application, 11, 524.

Glaser, B. G., \& Strauss, A. L. (1967). The discovery of Grounded Theory. Chicago: Aldine.

Goodboy, A. K. (2011). The development and validation of the instructional dissent scale. Communication Education, 60, 422-440.

Grinols, A. B., \& Rajesh, R. (2014). Multitasking with smartphones in the college classroom. Business \& Professional Communication Quarterly, 77, 89-95.

Hassoun, D. (2015). "All over the place": A case study of classroom multitasking and attentional performance. New Media \& Society, 17(10), 1680-1695.

Hembrooke, H., \& Gay, G. (2003). The laptop and the lecture: the effects of multitasking in learning environments. Journal of Computing in Higher Education, 15(1), 46-64.

Hsu, C. (2012). The influence of vocal qualities and confirmation of nonnative Englishspeaking teachers on student receiver apprehension, affective learning, and cognitive learning. Communication Education, 61, 4-16.

Jamal, A., \& Melkote, S. (2008). Viewing and avoidance of the Al-Jazeera satellite television channel in Kuwait: a uses and gratifications perspective. Asian Journal of Communication, 18, 1-15.

Jeong, S., \& Fishbein, M. (2007). Predictors of multitasking with media: Media factors and audience factors. Media Psychology, 10, 364-384.

Kearney, P., Plax, T. G., Richmond, V. P., \& McCroskey, J. C. (1985). Power in the classroom III: Teacher communication techniques and messages. Communication Education, 34, 19-28.

Kline, R. B. (2005). Principles and practice of structural equation modeling. New York: Guilford Press.

Krathwohl, D. R., Bloom, B. S., \& Masia, B. B. (1964). Taxonomy of educational objectives. Handbook II. New York: David McKay.

Lang, A. (2000). The limited capacity model of mediated message processing. Journal of Communication, 50, 46-70.

Lee, J., Lin, L., \& Robertson, T. (2012). The impact of media multitasking on learning. Learning, Media \& Technology, 37(1), 94-104.

Lewin, K. (1939). Field theory and experiment in social psychology: Concepts and methods. The American Journal of Sociology, 44, 868-896.

Journal of the Scholarship of Teaching and Learning, Vol. 17, No. 2, April 2017. josotl.indiana.edu 
Lysne, S. J. \& Miller, B.G. (2015). Using mobile devices to engage students in evolutionary thinking. The American Biology Teacher, 77 (8), 624-627.

MacCallum, R. C., Browne, M. W., \& Sugawara, H. M. (1996). Power analysis and determination of sample size for covariance structure modeling. Psychological Methods, 1 , 130-149.

Mahatanankoon, P., \& O'Sullivan, P. (2008). Attitude toward mobile text messaging: An expectancy-based perspective. Journal of Computer-Mediated Communication, 13, 973992.

Mayer, R. E. (1998). Cognitive, metacognitive, and motivational aspects of problem solving. Instructional Science, 26, 49-63.

Mayer, R. E. (2008). Old advice for new researchers. Educational Psychology Review, 20, 19-28.

McCroskey, J.C. (1994). Assessment of affect toward communication and affect toward instruction in communication. In S. Morreale \& M. Brooks (Eds.), 1994 SCA summer conference proceedings and prepare remarks (pp. 55-68). Annandale, VA: Speech Communication Association.

McCroskey, J. C., \& Richmond, V. P., Plax, T. G., \& Kearney, P. (1985). Power in the classroom: Behavior alteration techniques, communication training and learning. Communication Education, 34, 214-226.

McCroskey, J. C., \& Young, T. J. (1979). The use and abuse of factor analysis in communication research. Human Communication Research, 5, 375-382.

Moeller, S., Chong, E., Golitsinski, S., Guo, J., McCaffrey, R., Nynka, A., \& Roberts, J. (2010). A day without media. International Center for Media and the Public Agenda. Retrieved May 23, 2010, from http://withoutmedia.wordpress.com/

Olmsted, N.M., \& Terry, C. P. (2014). Who's texting in class? A look at behavioral and psychological predictors. Psi Chi Journal of Psychological Research, 19 (4), 183-190.

Park, H., Dailey, R., \& Lemus, D. (2002). The use of Exploratory Factor Analysis and Principal Components Analysis in communication research. Human Communication Research, 28, 562-577.

Patil, V. H., Singh, S. N., Mishra, S., \& Donavan, D. D. (2008). Efficient theory development and factor retention criteria: Abandon the "eigenvalue greater than one" criterion. Journal of Business Research, 61, 162-170.

Plax, T. G., Kearney, P., McCroskey, J. C., \& Richmond, V. P. (1986). Power in the classroom VI: Verbal control strategies, nonverbal immediacy and affective learning. Journal of the Scholarship of Teaching and Learning, Vol. 17, No. 2, April 2017. josotl.indiana.edu 
Rubenstein, J. S., Meyer, D. E., \& Evans, J. E. (2001), Executive control of cognitive processes in task switching. Journal of Experimental Psychology: Human Perception and Performance, 27, 763-797.

Rubin, A. M. (1994). Media uses and effects: A uses-and-gratifications perspective. In J. Bryant \& D. Zillmann (Eds.), Media effects: Advances in theory and research (pp. 417436). Hillsdale, NJ: Lawrence Erlbaum.

Sana, F., Weston, T. \& Cepeda, N.J. (2013). Laptop multitasking hinders classroom learning for both users and nearby peers. Computers and Education, 62, 24-31.

Shechtman, Z., \& Leichtentritt, J. (2004). Affective teaching: a method to enhance classroom management. European Journal of Teacher Education, 27, 323-333.

Skinner, E., Furrer, C., Marchland, G., \& Kindermann, T. (2008). Engagement and disaffection in the classroom: Part of a larger motivational dynamic? Journal of Educational Psychology, 100, 765-781.

Skinner, E. \& Belmont, M. (1993). Motivation in the classroom: Reciprocal effects of teacher behavior and student engagement across the school year. Journal of Educational Psychology, 85, 571-581.

Stephen, K. K. \& Davis, J. (2009). The social influences on electronic multitasking in organizational meetings. Management Communication Quarterly, 23, 63-83.

Tabachnick, B. G., \& Fidell, L. S. (2007). Using multivariate statistics (5th ed.). Boston: Allyn and Bacon.

Wei, F.F. \& Wang, Y.K. (2010). Students' silent messages: Can teacher verbal and nonverbal immediacy moderate student use of text messaging in class? Communication Education, 59, 475-496.

Young, J. R. (2006). The fight for classroom attention: Professor vs. laptop. Chronicle of Higher Education, 52(39), A27-A29.

Zhu, J., \& He, Z. (2002). Perceived characteristics, perceived needs, and perceived popularity: Adoption and use of the Internet in China. Communication Research, 29(4), 466-495. 